Advances in Geosciences, 2, 73-79, 2005

SRef-ID: $1680-7359 /$ adgeo/2005-2-73

European Geosciences Union

(c) 2005 Author(s). This work is licensed

under a Creative Commons License.

\title{
Impact of a high density GPS network on the operational forecast
}

\author{
C. Faccani ${ }^{1}$, R. Ferretti ${ }^{1,2}$, R. Pacione ${ }^{3}$, T. Paolucci ${ }^{1}$, F. Vespe ${ }^{4}$, and L. Cucurull ${ }^{5}$ \\ ${ }^{1}$ Department of Physics, University of L'Aquila, Italy \\ ${ }^{2}$ CETEMPS, University of L'Aquila, Italy \\ ${ }^{3}$ Telespazio SpA, Centro di Geodesia Spaziale, Matera, Italy \\ ${ }^{4}$ ASI, Centro di Geodesia Spaziale, Matera, Italy \\ ${ }^{5}$ COSMIC Project/JCSDA Suitland, MD, USA
}

Received: 24 October 2004 - Revised: 10 February 2005 - Accepted: 16 February 2005 - Published: 29 March 2005

\begin{abstract}
Global Positioning System Zenith Total Delay (GPS ZTD) can provide information about the water vapour in atmosphere. Its assimilation into the analysis used to initialize a model can then improve the weather forecast, giving the right amount of moisture and reducing the model spinup. In the last year, an high density GPS network has been created on the Basilicata region (south of Italy) by the Italian Space Agency in the framework of a national project named MAGIC2. MAGIC2 is the Italian follow on of the EC project MAGIC (Haase et al., 2001). Daily operational data assimilation experiments are performed since December 2003. The results show that the assimilation of GPS ZTD improves the forecast especially during the transition from winter to spring even if a no very high model resolution $(9 \mathrm{~km})$ is used.
\end{abstract}

\section{Introduction}

The water vapour has a large variability in space and time and it is important on all the microphysical processes. Therefore a good knowledge of its distribution is required to correctly initialize the weather forecast. An easy and cheap way to retrieve information on the moist content on atmosphere comes from the GPS (Global Positioning System) technology. The GPS signal from the satellite to the ground receiver is delayed by the ionosphere and the neutral atmosphere. While the ionospheric refraction is canceled out through observations at two different frequencies using as GPS observable the iono-free combination, the influence of the neutral atmosphere cannot be eliminated because of its non-dispersive behavior, and it has to be adequately modeled. The neutral atmosphere can be split into a dry and a wet component. The former is a function of the station height and surface pressure and it is easy to model. The latter depends on the atmospheric water vapour, which is highly variable in space and time and it is extremely difficult to model. The GPS-derived Zenith

Correspondence to: C. Faccani

(claudia.faccani@aquila.infn.it)
Wet Delay (ZWD) is proportional to the Integrated Precipitable Water Vapour (IPWV).

Therefore, the inclusion of this information into the weather forecast, can improve the knowledge of the humid parameters. Previous studies (Nakamura et al., 2004; Seko et al., 2004) show that the inclusion of the GPS Precipitable Water (GPS PW) can improve the forecast of the precipitation. Unfortunately, the retrieval of the water vapour depends on the correct knowledge of the surface pressure and barometers are not always available at the GPS antenna site. To avoid this problem the assimilation of the ZTD has to be performed. Vedel and Huang (2004) and Peng and Zou (2004) show that the assimilation of ZTD produces small improvements on the forecast of the precipitation. In the first case, the higher spatial resolution of the model grid is of about $28 \mathrm{~km}$ and the GPS distribution is of the order of tenth of kilometers. In the second case the grid resolution is of $6 \mathrm{~km}$ and the distance among the GPS receivers is about $20 \mathrm{~km}$. In this paper, our goal is to investigate the role of a high density GPS network on the precipitation forecast using a $9 \mathrm{~km}$ model grid resolution.

\section{GPS data}

The signal from the GPS satellite to the ground-based receivers is delayed by the atmosphere, depending on temperature, pressure and water content (Smith and Weintraub, 1953). In the Zenith direction, the delay can be written as

$Z T D=\Delta L_{z}=10^{-6} \int k_{1} \frac{P}{T}+k_{2} \frac{e}{T}+k_{3} \frac{e}{T^{2}}$

where $k_{1}, k_{2}$ and $k_{3}$ are the refractivity constants, $T$ is the Temperature, $P$ is the pressure of dry atmosphere and $e$ is the partial pressure of water vapour. The delay is mostly due to the induced atmospheric dipole momentum (hydrostatic delay of about $2300 \mathrm{~mm}$ at the sea level) and the permanent dipole momentum of the water vapour (wet delay of about $100 \mathrm{~mm}$ at the sea level). Ices and liquid water contributions 


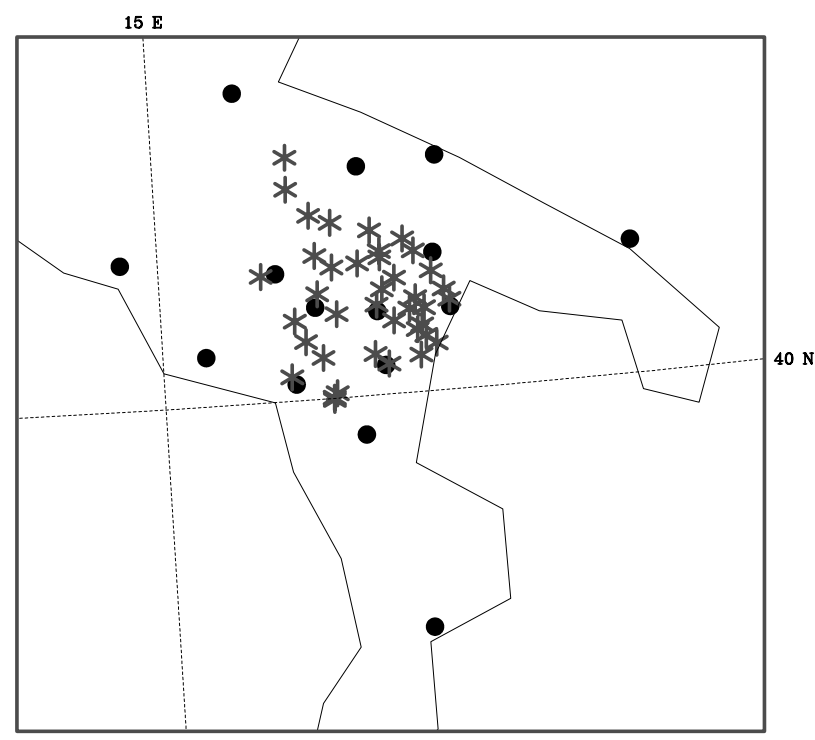

Fig. 1. Distribution of GPS ground-based antennas (black dots) and pluviometers (dark gray asterisks) on the high resolution domain.

can be neglected because they are smaller than $1 \%$ of the wet delay. The magnitude of the wet delay is ten times smaller than the hydrostatic one, but it provides information about the water vapour content in atmosphere.

In the last year, a network of 15 GPS ground-based receivers has been created in the south of Italy as shown in Fig. 1 (black dots). The position of each station has been choosen to produce a wide coverage and to monitor those areas with a complex orography, such as the downslope of the mountains and the valleys.

The GPS data reduction is performed using the GIPSYOASIS II by point positioning mode (Zumberge et al., 1997) fixing Jet Propulsion Laboratory (JPL) fiducial-free satellite orbits, clocks and earth orientation parameters. ZTD estimates, with a sampling rate of $5 \mathrm{~min}$, are averaged over $15 \mathrm{~min}$ and converted into a standard meteorological data format (Offiler, 2003). The Niell (1996) dry and wet mapping function and the ocean loading corrections Scherneck (1991) are applied. The information on the antenna phase center variation provided by the International GPS Service (IGS) are applied as well. A description of the GPS processing is given in Pacione et al. (2001) and Pacione and Vespe (2003).

\section{3DVAR}

A time indipendent variational data Assimilation technique (3DVAR) has been used to assimilate the GPS ZTD on the NCEP analysis, used as First Guess. 3DVAR (Courtier et al., 1998; Gustafsson et al., 2001; Barker et al., 2004) produces improved initial conditions by minimizing the function

$J=\frac{1}{2}\left(x^{b}-x\right)^{T} \mathbf{B}^{-1}\left(x^{b}-x\right)+$

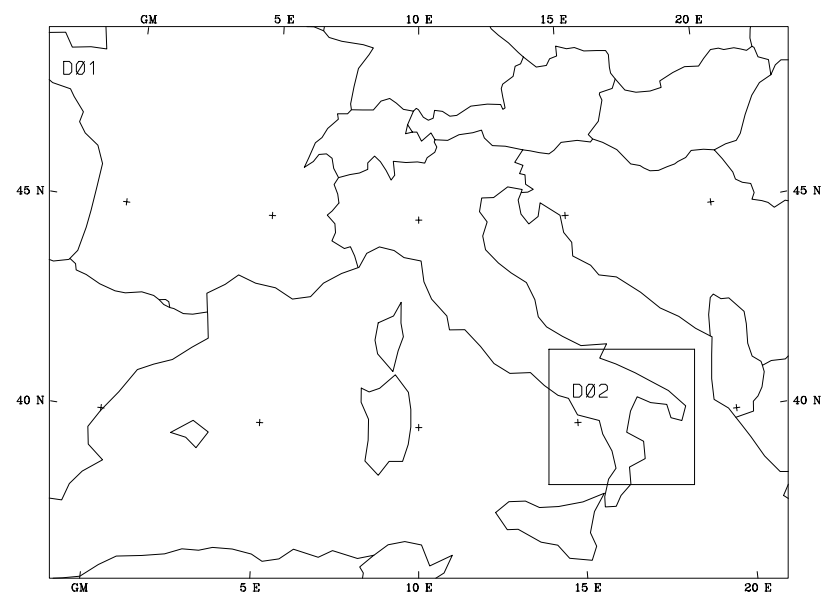

Fig. 2. Model domains used for the operational forecasts.

$$
\frac{1}{2}\left(y^{o}-H\left(x^{b}\right)\right)^{T} \mathbf{R}^{-1}\left(y^{o}-H\left(x^{b}\right)\right)
$$

where $x^{b}$ is the generic variable of a priori state (first guess), $y^{o}$ is the observation, and $H$ is the operator that converts the model state variables to the observed variables at the observation location. $\mathbf{B}$ and $\mathbf{R}$ are the error covariance matrices for the first guess and for the errors, respectively.

The assimilation of GPS ZTD has been recently implemented in 3DVAR (Cucurull et al., 2004).

\section{Model setup}

The model used is MM5 from PSU/NCAR (Grell et al., 1994; Dudhia, 1993). The Kain and Fritsch (1990) cumulus convection scheme is used together with the explicit moisture scheme Reisner et al. (1998). The Planetary Boundary Layer is described by the Hong and Pan (1996) and Troen and Mahrt (1986) parameterization. 30 vertical $\sigma$ layers are used. The domains configuration is showed in Fig. 2. The resolution of the domains is $27 \mathrm{~km}$ for D1 and $9 \mathrm{~km}$ for domain 2.

Two experiments per day are performed. The first one, CNTR, is used as reference and the second one, EXP, has the Initial Conditions Improved by the assimilation of GPS ZTD. The experiments start at 1200UTC of each day and they end after $36 \mathrm{~h}$.

\section{Results}

The validation of the model results has been evaluated using the Mean error and the RMS defined as

$M=\frac{\sum_{i}^{N}\left(O B S_{i}-I C_{i}\right)}{N}$ 


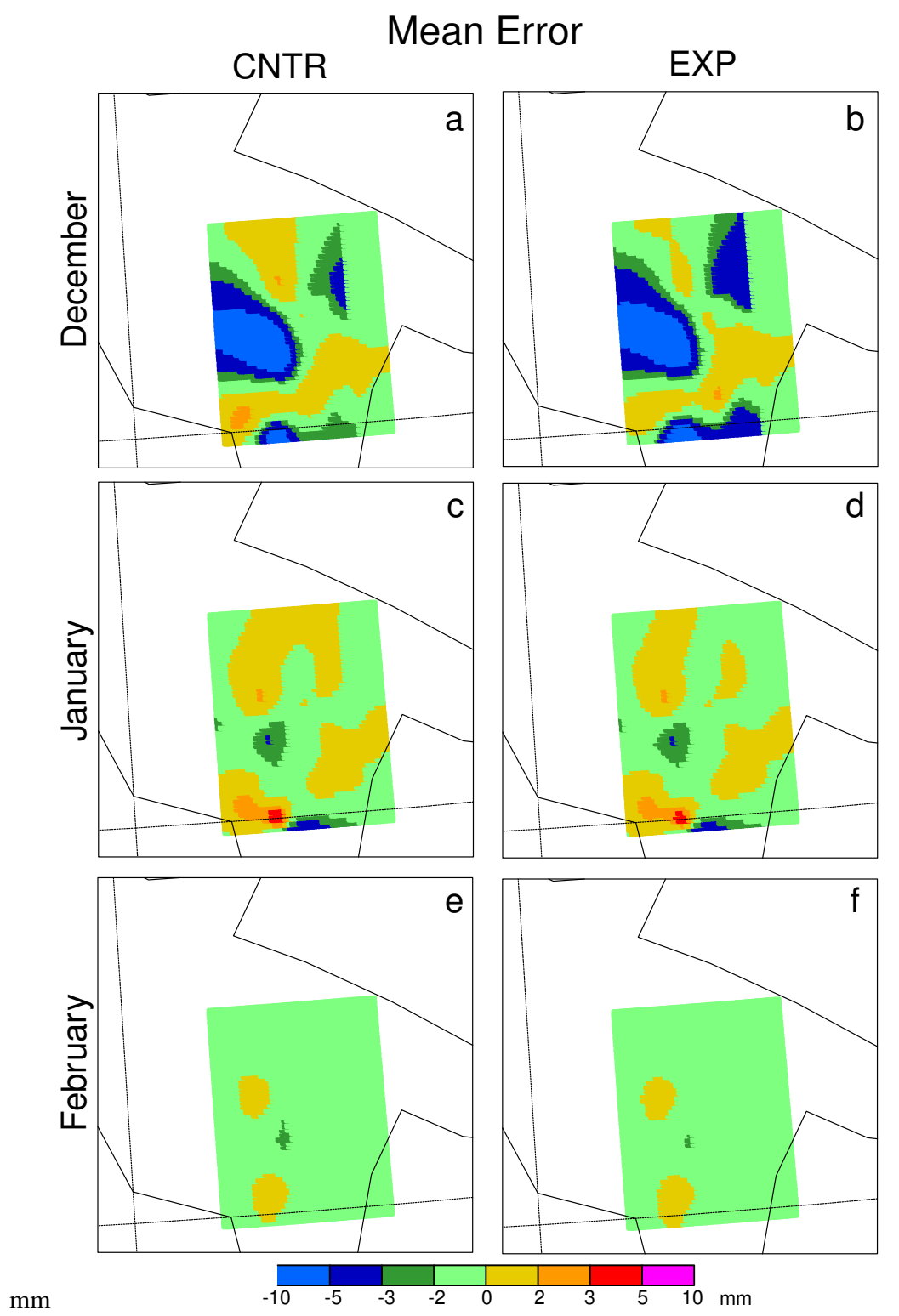

Fig. 3. Mean error for the Winter season from December 2003 (top) to February 2004 (bottom) for CNTR (left column) and EXP (right column).

and

$$
R M S=\sqrt{\frac{\sum_{i}^{N}\left(O B S_{i}-I C_{i}\right)^{2}}{N} .}
$$

where OBS is the observation and IC is the analysis at the $i t h$ station location. The observed precipitation is used for the validation. The distribution of the pluviometers which provided the data are the dark gray asterisks in Fig. 1. Average mean errors and RMS have been evaluated for the winter season, from December 2003 to the end of February 2004, and the spring season, from March to the end of May 2004. They are showed in Figs. 3, 4, 5, and 6. The Mean error shows that during December 2003 (Fig. 3a, b) CNTR produces an underestimation (orange in Fig. $3 \mathrm{a}$ ) of the precipi- tation close to the west side of the Apennines (bottom left). This error is reduced and shifted eastward if ZTD from GPS is assimilated into the model (EXP, Fig. 3b). Moreover it reduces the underestimation on the top of the domain. On the other hand, EXP overestimates (blue areas) the precipitation on the southern and eastern domain. On January (Fig. 3c, d) EXP produces improvements on the top of the domain only, and no remarkable changes are found for February (Fig. 3e, f). In March (Fig. 4a, b) the assimilation of ZTD from GPS reduces the overestimation (blue) on the bottom of the domain (Fig. 4b) respect to CNTR (Fig. 4a), and it largely reduces the underestimation area (red) on the bottom left corner, showing a good agreement with the observations. This is probably due to the increasing amount of humidity available during this month (passage from winter to spring) that it 


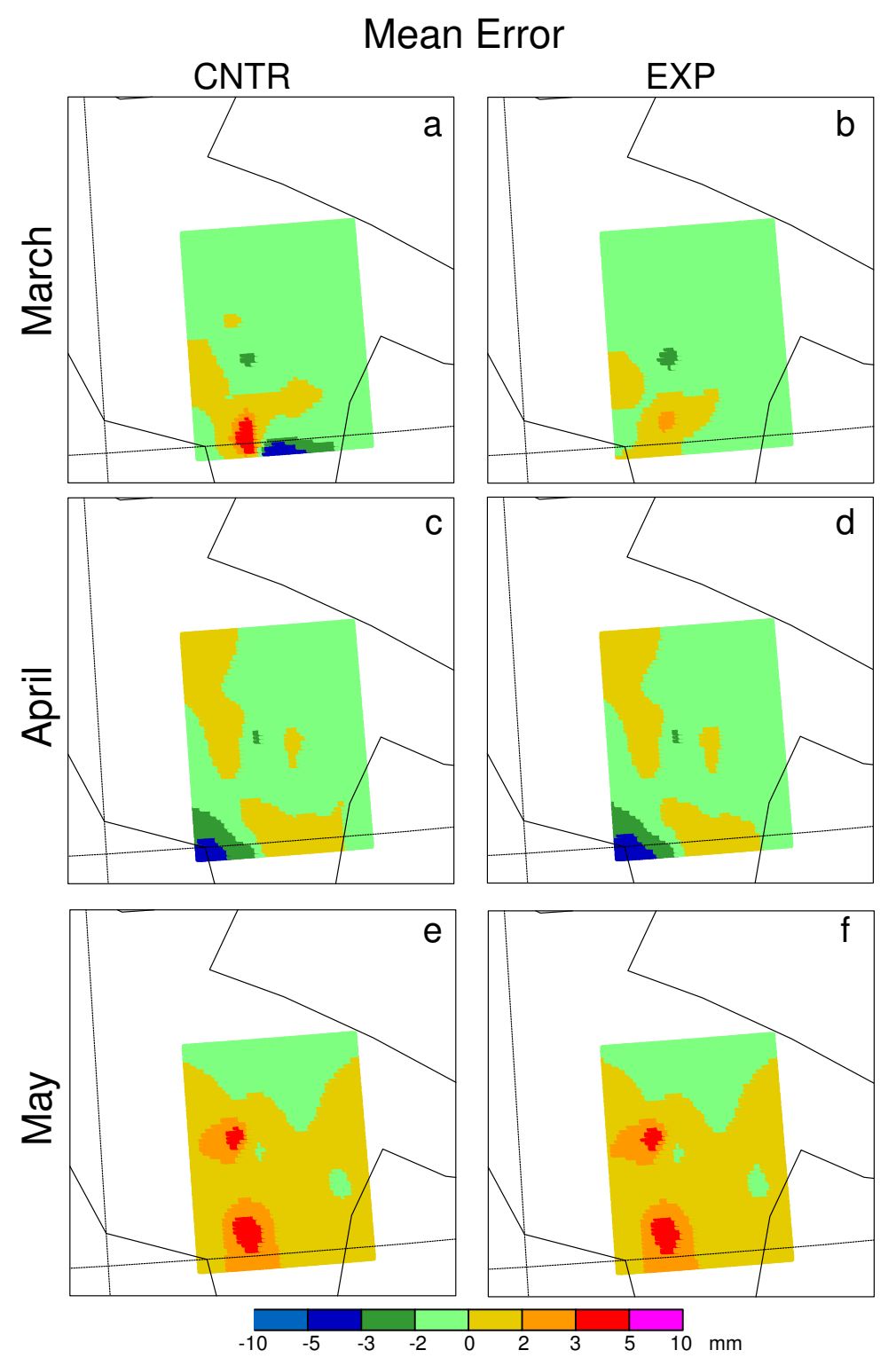

Fig. 4. Mean error for the Spring season from March 2004 (top) to May 2004 (bottom) for CNTR (left column) and EXP (right column).

is not correctly reproduced by the NCEP analysis, but it can be provided to the model by assimilation of GPS ZTD. April (Fig. 4c, d) and May (Fig. 4e, f) do not show any remarkable difference between CNTR and EXP. This is probably due to the high precipitation occurred during these months: as explained in paragraph 2, ice and liquid water are negligible in the ZTD computation; therefore, when it rains, the water vapour availability in atmosphere is largely reduced and it mostly exists as cloud liquid water and raining drops. In Spring 2004, April and May had respectively 28 and 23 rainy days.

EXP shows, for December, a reduction of the RMS maximum (purple, Fig. 5b) respect to CNTR (Fig. 5a), on the left side of the domain and on the right side (from magenta to red), but an increase of the error (light green) on the top right corner is found. Simirlary to the Mean error, EXP (Fig. 5d) shows a reduction of the error on the top left of the domain of January, but no remarkable changes are found between CNTR and EXP for February (Fig. 5e, f). March (Fig. 6a, b) confirms the large improvement of EXP (Fig. 6b) respect to CNTR (Fig. 6a) removing the maximum on the bottom left corner of the domain. During April (Fig. 6c, d) and May (Fig. 6e, f) the ZTD assimilation does not produce any improvement.

\section{Conclusions}

The assimilation of the GPS ZTD has been performed operationally since December 2003, using the data produced by the high density ground-based receivers on the south of Italy. The distribution of the antennas (black dots in Fig. 1 


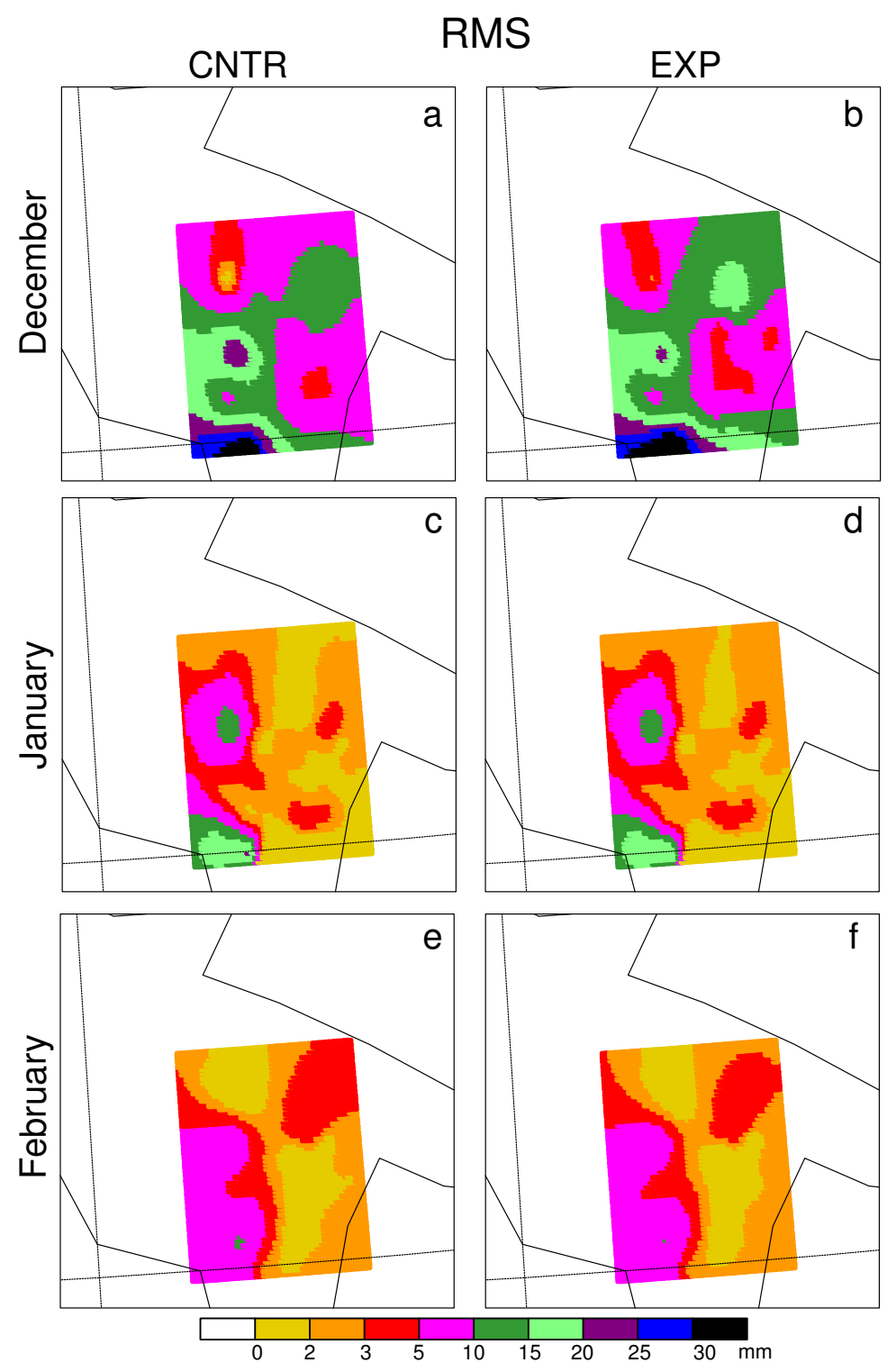

Fig. 5. RMS for the Winter season from December 2003 (top) to February 2004 (bottom) for CNTR (left column) and EXP (right column).

has been decided to cover those areas of complex orography and the downslope of the Apennines. NCEP data are used to initialize the MM5 model with 2 nested domains (27 and $9 \mathrm{~km}$ in Fig. 2). Two daily experiments are performed; the first one, CNTR, is used as reference and no data assimilation is performed. The second one, EXP, uses the Initial Conditions improved by the assimilation of GPS ZTD. Results show that the assimilation of ZTD, that provides information on the atmospheric water vapour content, improves the forecast during the transition between winter and spring, when the release of the water vapour increases. Because of liquid water and ice do not give any contribution to ZTD, the raining months such as April and May 2004, do not show any remarkable changes between the corresponding CNTR and EXP. It has to be pointed out that this study has been performed using a low resolution of the model domains, i.e.
$9 \mathrm{~km}$. Usually, this resolution is considered to be too low to produce a valuable improvement on the forecast if GPS ZTD data from a low density network are used and no assimilation of local observations is performed (Cucurull et al., 2004). It suggests that a low model resolution and a high density GPS network work as a high resolution model and a low density network, even if other observations are not assimilated. Moreover, this configuration reduces the computational costs.

Acknowledgements. Thanks to ALSIA Basilicata for the observation used for the analysis of our results. Thanks to TIM (Telecom Italia Mobile) for the data of its GPS network.

Edited by: L. Ferraris

Reviewed by: C. Adamo and R. Rudari 

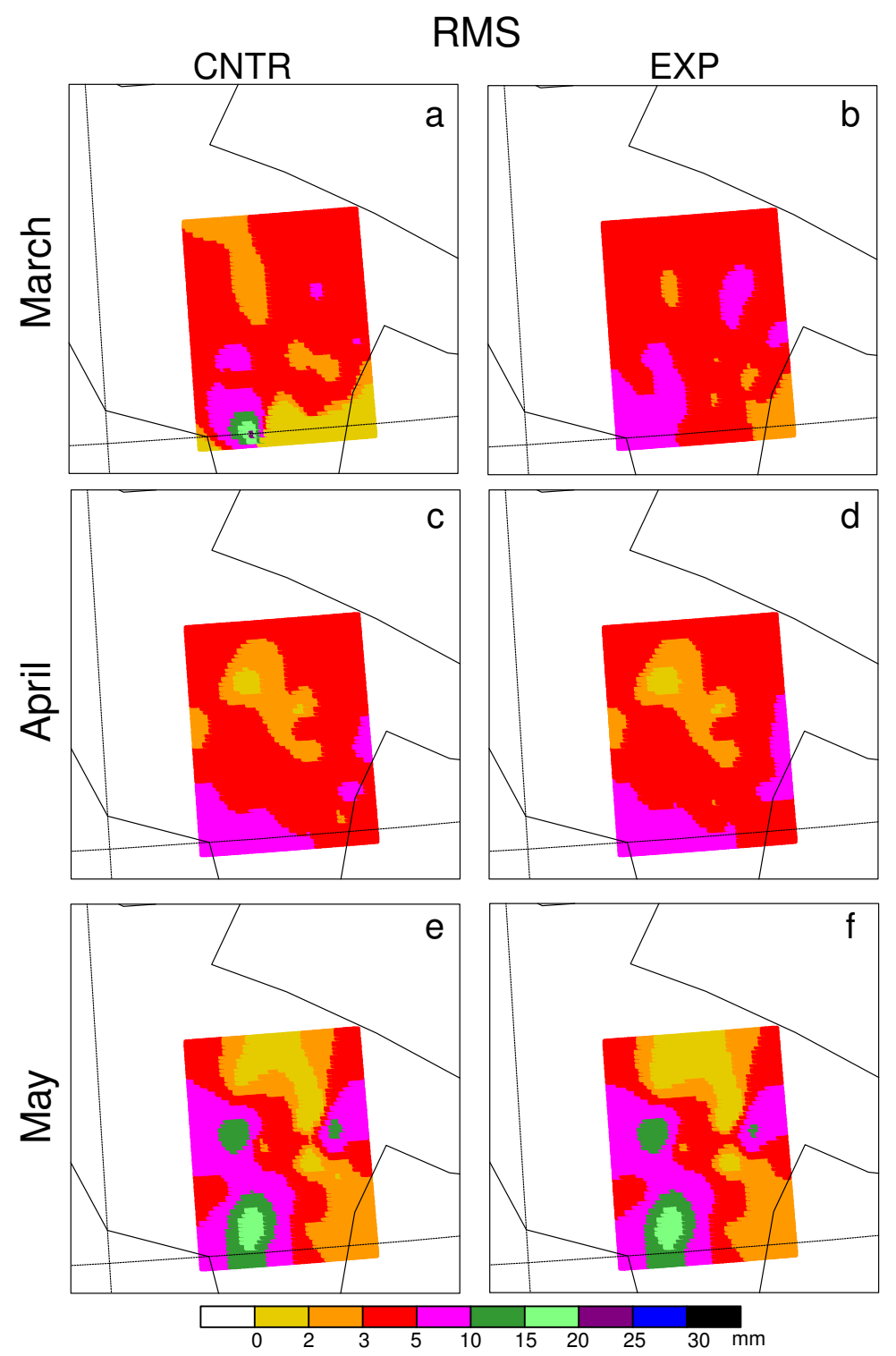

Fig. 6. RMS for the Spring season from March 2004 (top) to May 2004 (bottom) for CNTR (left column) and EXP (right column).

\section{References}

Barker, D. M., Huang, W., Guo, Y.-R., Bourgeois, A., and Xiao, Q.: Three-Dimensional Variational Data Assimilation System for MM5: Implementation and initial results, Mon. Wea. Rev., 132, 897-914, 2004.

Courtier, P., Anderson, E., Heckley, W., Pailleux, J., Vasiljeric, D., Hamrud, M., Hollingsworth, A., Rabier, F., and Fisher, M.: The ECMWF implementation of three-dimensional variational assimilation (3D-Var). I: Formulation., Q. J. R. Meteorol. Soc., 124, 1783-1807, 1998.

Cucurull, L., Vandenberghe, F., Barker, D., Vilaclara, E., and Rius, A.: Three-Dimensional Variational Data Assimilation of Ground-Based GPS ZTD and Meteorological Observations during the 14 December 2001 Storm Event over the Western Mediterranean Sea, Mon. Wea. Rev., 132, 749-763, 2004.

Dudhia, J.: A nonhydrostatic version of the Penn State-NCAR Mesoscale Model: Validation tests and simulation of an Atlantic cyclone and cold front, Mon. Wea. Rev., 121, 1493-1513, 1993.

Grell, G., Dudhia, J., and Stauffer, D.: A Description of the FifthGeneration Penn State/NCAR Mesoscale Model (MM5)., NCAR Tech. Note NCAR/Tn-398+STR, 1994.

Gustafsson, N., Berre, L., Hörnqvist, S., Huang, X.-Y., Lindskog, M., B.Navascue, Mogensen, K. S., and Thorsteinsson, S.: Three-dimensional variational data assimilation for a limited area model. Part I: General formulation and the background error constraint, Tellus, 53A, 425-446, 2001.

Haase, J., Calais, E., Talaya, J., Rius, A., Vespe, F., Santangelo, R., Huang, X.-Y., Davila, J., Ge, M., Cucurull, L., Flores, A., Sciarretta, C., Pacione, R., Boccolari, M., Pugnaghi, S., Vedel, H., Mogensen, K., Yang, X., and Garate, J.: The Contributions of the MAGIC Project (Meteorological Applications of GPS Integrated Column Water Vapor Measurements in the Western Mediterranean) to the COST 716 objectives of assessing the operational potential of ground-based GPS meteorology on an international scale., Phys. Chem. Earth (A), 26, 433-437, 2001. 
Hong, Y. and Pan, H.: Non-local Boundary Layer vertical diffusion in a medium range forecast model, Mon. Wea. Rev., 124, 23222339, 1996.

Kain, J. S. and Fritsch, J. M.: A one-dimensional entraining/detraining plume model and its application in convective parameterization, J. Atmos. Sci., 47, 2784-2802, 1990.

Nakamura, H., Koizumi, K., and Mannoji, N.: Data assimilation of GPS precipitable water into the JMA Mesoscale Numerical Weather Prediction Model and its impact on the rainfall, J. Met. Soc. J., 82, 441-452, 2004.

Niell, A.: Global mapping functions for the atmospheric delay at radio wavelengths, J. Geophys. Res., 101, 3227-3246, 1996.

Offiler, D.: Format Specification for COST-716 Processing GPS Data, Version 2.0a, http://www.oso.chalmers.se/ $\sim$ kge/cost716. html, 2003.

Pacione, R. and Vespe, F.: GPS Zenith Total Delay Estimation in the Mediterranean Area for Climatological and Meteorological Applications, J. Atmos. Oceanic Tech., 20, 1034-1041, 2003.

Pacione, R., Sciarretta, C., Vespe, F., Faccani, C., Ferretti, R., Fionda, E., Ferraro, C., and Nardi, A.: GPS Meteorology: validation and comparisons with round-based microwave radiometer and mesoscale model for the Italian GPS permanent stations, Phys. Chem. Earth (A), 26, 139-145, 2001.

Peng, S.-Q. and Zou, X.: Impact on short-range precipitation forecast from assimilation of ground-based GPS zenith total delay and rain gauge precipitation observations, J. Met. Soc. J., 82, 491-506, 2004.
Reisner, J., Rasmussen, R., and Bruintjes, R.: Explicit forecasting of supercooled liquid water in winter storms using the MM5 mesoscale model, Q. J. R. Meteorol. Soc., 124B, 1071-1107, 1998.

Scherneck, H.-G.: A parameterized solid earth tide model and ocean tide loading effects for global geodetic measurements, Geophys. J. Int., 106, 677-694, 1991.

Seko, H., Kawabata, T., Tsuyuki, T., Nakamura, H., Koizumi, K., and Iwabuchi, T.: Impacts of GPS-derived water vapor and radial wind measurements by doppler radar on numerical prediction of precipitation, J. Met. Soc. J., 82, 473-489, 2004.

Smith, E. and Weintraub, S.: The constants in the equation for atmospheric refractive index at radio frequencies. Proceedings of I.R.E., August, Vol. 4, 1953.

Troen, I. and Mahrt, L.: A simple model of the atmospheric boundary layer: Sensitivity to surface evaporation., Bound.-Layer Meteor., 37, 129-148, 1986.

Vedel, E. and Huang, X.-Y.: Impact of Ground Based GPS data on numerical weather prediction, J. Met. Soc. J., 82, 459-472, 2004.

Zumberge, J., M.B. Heflin and, D. J., Watkins, M., and Webb, F. H.: Precise point positioning for the efficient and robust analysis of GPS data from large networks, J. Geophys. Res., 102, 50055017, 1997. 